\title{
Assessment of 3 Tac-I/Beta, an Antimicrobial Peptide Source, in the Control of Pseudomonas Plant Pathogens
}

\author{
Moya-Elizondo E. A. ${ }^{1 *}$, Quezada $\mathrm{T}^{1}$, Reyes Salinas $\mathbf{M}^{2}$ and Reyes Navarro M. A. ${ }^{2}$ \\ ${ }^{1}$ Department of Vegetal Production, University of Concepción, Chile \\ ${ }^{2}$ AVance Biotechnologies, Chile
}

*Corresponding author: Moya Elizondo EA, Department of Plant Production, Faculty of Agronomy, Universidad de Concepción, Chillán, Chile

To Cite This Article: Moya-Elizondo EA, Quezada T, Reyes Salinas M, Reyes Navarro MA. Assessment of 3 Tac-I/Beta, an Antimicrobial Peptide Source, in the Control of Pseudomonas Plant Pathogens. Am J Biomed Sci \& Res. 2019 - 2(1). AJBSR.MS.ID.000564.

DOI: 10.34297/AJBSR.2019.02.000564

Received: March 14, 2019 | Published: March 21, 2019

\begin{abstract}
Diseases caused by Pseudomonas syringae and other species of Pseudomonas cause severe losses in different fruit crops worldwide. Antimicrobial peptides (AMPs) are small and consist of a variety of proteins that act on the lipid bilayer of the bacterial membrane that is produced by multicellular organisms. The product, 3 Tac-I/Beta, is a biopesticide that bases its action on three Trichoderma strains (T. viride strain T-26, T. harzianum strain T-22, and T. longibrachiatum strain T-397), its total concentration is $>25 \times 10^{3}$ c.f.u. $\mathrm{g}^{-1}$, which is authorized in Chile to control different fungal diseases in fruit and vegetable crops. However, the reduction of bacterial stone canker disease has suggested a possible AMPs mode of action associated with 3 Tac-I/Beta. In this study we used Transmission Electronic Microscopy (TEM) to assess the possible AMP activity of this product on the bacterial membrane of Pseudomonas syringae pv. syringae (Pss). The effect of two filtered solutions of 3 Tac-I/Beta (commercial and concentrated) on the population of this bacterium was assessed by using in vitro tests.
\end{abstract}

Control on this bacterial plant pathogen in cherry plants cv. Bing treated with 3 Tac-I/Beta, copper hydroxide, and copper oxide was assessed in a pot experiment. This TEM study showed a marked damage on the membrane of $P$. syringae pv. syringae, which affected the bacillus shape of the bacterium by changing the continuity of its membrane. In vitro tests on a homogeneous lawn of Pss showed the formation of inhibition halos around discs treated with filtered 3 Tac-I/Beta across the surface of agar King B-medium plates. Reduction in the bacterial population after 18 hours of bacterial growth in King B medium amendment with a solution of commercial and concentrated filtered of 3 Tac-I/Beta were observed. Bacterial growth, expressed as the optical density of cell culture, was reduced by around $12 \%$ when 3 Tac-I/Beta was used, while a concentrated AMP solution of filtered 3 Tac-I/Beta showed a reduction of around 34.8\% after 18 hours of co-culture. The effect on bacterial growth was maintained for 30 hours for both filtered solutions of the product. Preventive spraying of 3 Tac-I/Beta on cherry plants cv. 'Bing', which were wounded and inoculated with Pss 24 hours after spraying, showed differences in the length of the bacterial canker compared to the untreated control. The biopesticide treatment was no different from the copper based treatments $(\mathrm{P}<0.10)$. The potential use of 3 Tac-I/Beta as an alternative to control kiwifruit canker is further discussed below.

Keywords: Pseudomonas syringaepv. syringae; Antimicrobial peptides; Bacterial fruit canker; Biocontrol; 3 Tac-I/Beta

\section{Introduction}

Some species of Pseudomonas syringae and other Pseudomonas are among the most important plant pathogens, causing severe losses in different fruit crops worldwide (Kennelly et al., 2007). Recently, an outbreak of $P$. syringae pv. actinidiae (Psa), the causal agent of the bacterial canker in kiwifruit (Actinia spp.), has increased interest in developing and assessing new alternatives to control Pseudomonad phytopathogens. Although the aforementioned outbreak occurred in New Zealand, PSa has caused severe losses around the world [1]. In Chile, the bacterial kiwi canker affects around 163 orchards including 1,824 hectares dedicated to the production of kiwifruit between the O'Higgins and the Biobío Regions. Among the alternatives to control this disease, the most effective alternative has been the use of copper based products, antibiotics, resistance inducers, and cultural practices associated with reducing the favorable conditions available to this bacterial disease [1-2]. Copper based products are undergoing increased regulations in European markets, while antibiotics are completely prohibited in some markets [2]. Acybenzolar-S-Methyl (Actigard $\AA$ or Bion $\AA$, Syngenta) is a new alternative; however, it is expensive and cannot be used in organic orchards to control bacterial diseases. 
Cameron \& Sarojini [3] have also proposed the use of chitosan and antimicrobial peptides (AMPs) as an alternative to developing new strategies to control PSa.

AMPs are small and consist of a variety of proteins that act upon the lipid bilayer of the bacterial membrane produced by multi cellular organisms. In theory, many AMPs selectively target the lipid bilayer membrane of bacteria. In Gram-negative bacteria, such as Pseudomonas species, the anionic outer surface of bacterial membranes provides a selective binding site for cationic AMPs [3].

P. syringae pv. syringae is an important bacterial plant pathogen that affects several species of plants, causing bacterial canker in sweet cherry trees [4]. This phyto bacterium can also affect kiwifruit plants. In Chile, stone bacterial canker is one of the most important bacterial diseases in the fruit production industry, and the same control restrictions described for the kiwifruit's bacterial canker apply to this disease. The Biotechnological company AVance Biotechnologies S.A. has recently developed the product "3 Tac-I/Beta", which is a biopesticide authorized in Chile to control different fungal diseases in fruit and vegetable crops. 3 Tac-I/Beta was patented in Europe in 2008 (EP 1384405 B1) as a bactericidal, bacteriostatic and fungicide based on the coexistence, cohabitation and mutual repulsion of two or more living species of Trichoderma. This product is based on three Trichoderma species: T. viride strain T-26, T. harzianum strain T-22 and T. longibrachiatum strain T-397( $25 \times 10^{3}$ c.f.u. $\mathrm{g}^{-1}$ ) in a ratio of $10: 20: 70$ or $90: 05: 05$. Among the Trichoderma species, the T. longibrachiatum strain was obtained by micro expositions of cobalt over 50 generations. This Trichoderma mutant is not affected by the secretion released by the other two species of Trichoderma found in the mixture, avoiding the annihilation of the fungal species when they live together in the culture. Additionally, the powder mixture of this biopesticide contains $0.68 \mathrm{mg} \mathrm{mL}^{-1}$ of a hydro alcoholic extract of Rubus sp., and micro traces of streptomycin and auxin, which allow this product to have some bactericidal and bacteriostatic activity. However, empirical observations under field conditions utilizing 3 Tac-I/Beta have shown a high reduction of bacterial stone canker disease. The production of lytic enzymes corresponding to carboxymethylcellulase, chitinase, $\beta$-1, 3-glucanase, $\beta$-xylosidase, xylanase and 6-pentyl- $\alpha$-pirone, have suggested a possible AMPs mode of action associated with this product.

This research was conducted with the objective to assess the possible AMP activity of 3Tac-I/Beta on the bacterial membrane of a Pseudomonas plant pathogen by using Transmission Electronic Microscopy (TEM). Moreover, the effect of these filtered solutions on the population of this bacterium was assessed by using in vitro tests and the pure product was assessed for its effectiveness in controlling this bacterial pathogen in cherry plants under controlled conditions.

\section{Materials and Methods}

\section{Microbial material}

In vitro work was conducted on the strain of P. syringae $p v$. syringae (Pss) PS3, which was isolated from infected branches obtained from a sweet cherry cv. Lapins orchard located in Pueblo
Seco, in the Ñuble Region (GPS: 36 $53^{\prime} 47^{\prime \prime}$ S; $72^{\circ} 08^{\prime} 57^{\prime \prime}$ W) of Chile. This bacterial strain fluoresces under UV light in King B medium, and shows high pathogenicity on green beans and lemon fruits. Additionally, this species' identity was confirmed by the amplification of the $16 \mathrm{~S}$ rRNA by using primers $8 \mathrm{~F}$ and $1492 \mathrm{~F}$ [5].This DNA product was sequenced in Macrogen (Seoul, Korea) and an in silico comparison was conducted using the BLAST tools available in the National Center of Biotechnology Information (NCBI) in the United States. Strain PS3 had a 97\% homology with accession ID. KF500097, from the GenBank, associated with $P$. syringaepv. syringae strain $\mathrm{HH}-02$.

\section{In vitro trial to assess effect on Pss colonies}

Solutions of $10 \mathrm{~g}$ per $1 \mathrm{~L}$ of the commercial product 3Tac-I/ Beta and of a concentrated formulation with four times the concentration of polypeptides present in 3Tac-I/Beta $(4 \times 3$ Tac-I/ Beta) were filtered separately with $2 \mu \mathrm{m}$ Millipore filters and used in an antibiosis test. Ten $\mu \mathrm{L}$ of each solution plus a treatment with copper oxide (Nordox ${ }^{\circledR} 75 \mathrm{WP}, 0.2 \mathrm{~g} 100 \mathrm{~mL}^{-1}$ ) and a control of distilled sterile water were individually and equidistant placed into filter paper disks of $5 \mathrm{~mm}$ in diameter, which were established on a bacterial lawn of Pss PS3 grown on agar King B medium. Pss PS3 was inoculated previously to place the filter paper disks with each treatment. Plates were incubated for $48 \mathrm{~h}$ at $25^{\circ} \mathrm{C}$, after which the inhibition area of each treatment was determined. Four Petri plates were used and the experiment was repeated twice.

The effect of 3Tac-I/Beta solutions was assessed on populations of Pss in microplates of 96 wells of $250 \mu \mathrm{L}$. Two $\mu \mathrm{L}$ of a suspension of fresh bacteria ( 107 c.f.u $\mathrm{mL}^{-1}$ ) were placed in $98 \mu \mathrm{L}$ of the following three treatments: sterile distilled water, and a filtered solution of $10 \mathrm{~g} \mathrm{~L}^{-1}$ of commercial 3Tac-I/Beta and one of its concentrated formulation (4x3Tac-I/Beta). These mixtures were left for 24 hours at $25^{\circ} \mathrm{C}$ in an incubation chamber, and then inoculated with 100 $\mu \mathrm{L}$ of King B broth. Afterwards, the optical density (absorbance) at $600 \mathrm{~nm}$ was determined at $0,2,4,6,18,24,26,28,30$, and 48 hours by using a microplate reader (RayltoRT-2100C). Controls of spectro photometric bias were established by replacing the $2 \mu \mathrm{L}$ of bacteria in the cells by treatments with the same amount of sterile King B broth. Treatments and spectro photometric controls were replicated in 12 wells and the experiment was repeated twice.

\section{Assessment of direct damage of 3Tac-I/Beta on bacterial cell membrane by using TEM}

The effect of the 3 Tac-I/Beta product and the control were assessed by preparing tubes with $1.5 \mathrm{~mL}$ of each treatment plus 3 $\mathrm{mL}$ of King B broth medium and $0.5 \mathrm{~mL}$ of a bacterial suspension with the bacterial strain PS3, which was previously grown in the same media for 24 hours at $24^{\circ} \mathrm{C}$ with $200 \mathrm{rpm}$ of agitation. Tubes were prepared in triplicate and incubated under the same previously described conditions for 5 days. Samples of $1 \mathrm{~mL}$ of the bacterial culture obtained in each tube were fixed in $2.5 \%$ glutaraldehyde in a $0.1 \mathrm{M}$ phosphate buffer $(\mathrm{pH} 7.2)$ for $1 \mathrm{~h}$ at $4{ }^{\circ} \mathrm{C}$ and post-fixed in $1 \%$ osmium tetroxide in the same buffer for 1 h. The samples were dehydrated in a graded ethyl alcohol series, followed by two changes of propylene oxide, and embedded in araldite resin. Sections were made on Sorvall ultramicrotome with 
a glass knife and stained by drops of $2 \%$ uranyl acetate followed by lead citrate for $30 \mathrm{~min}$. Sections were examined in a JEOL JEM 1200EX II transmission electron microscope at an accelerating voltage of $80 \mathrm{kV}$.

\section{In plant experiment}

The preventive and curative activity of the commercial product 3Tac-I/Beta was assessed on cherry plants cv. Bing obtained from a nursery. Individual plants were wounded with a sterile knife in four places along the main axe and divided into two sections. The lower section was the preventive section, which was sprayed with the treatments (Control, 3 Tac-I/Beta alone and 3 Tac-I/Beta plus a biosurfactant [Biotens ${ }^{\circledR}$ ], Copper hydroxide and copper oxide in commercial dosages). Wounds were then inoculated after $24 \mathrm{~h}$ with $50 \mu \mathrm{L}$ of a suspension of $10^{8}$ u.f.c. of strain PS3 $/ \mathrm{ml}$. At the top section, wounds were inoculated as described and treated with treatments after 24 hours. Treatments consisted of a control sprayed with distillated sterile water, 3Tac-I/Beta alone $\left(300 \mathrm{~g} \mathrm{hL}^{-1}\right)$, 3Tac-I/Beta (300 $\left.\mathrm{g} \mathrm{hL}^{-1}\right)$ plus Biotens ${ }^{\circledR}\left(0.05 \mathrm{~L} \mathrm{hL}^{-1}\right)$, copper hydroxide in doses of $200 \mathrm{~g} / \mathrm{hL}$, and a solution of $250 \mathrm{~g} / \mathrm{hL}$ of copper oxide. Five plants were used as replicates for each treatment.

Plants were maintained for 5 months individually in pots in a room chamber with $14 \mathrm{~h}$ of light and $10 \mathrm{~h}$ of darkness. At the end of this period, $15 \mathrm{~cm}$ pieces of plant stems were cut around the site of inoculation. They were then opened in the center to observe and measure the length of the canker or damaged area formed in the tissue around the inoculated wound.

\section{Results and Discussion}

In vitro tests on a homogeneous lawn of Pss showed the formation of small inhibition halos around discs treated with the filtered obtained from the commercial formulation of 3 Tac-I/Beta (2,3 $\mathrm{mm}$ on average) across the surface of agar King B medium plates. These halos were significantly different from the control treated with distillated sterile water $(\mathrm{P}<0.05)$. However, the inhibition halos obtained with the copper oxide solution raised the inhibition radio to $18.2 \mathrm{~mm}$, which was about nine times higher than that created by 3 Tac-I/Beta. These results suggest that the lytic enzymes present in 3 Tac-I/Beta had difficulty diffusing into the agar matrix compared to the copper ion released by copper oxide. However, the assessment of 3 Tac-I/Beta's effect on bacterial populations by using optical density readings showed differences among the filtered solutions obtained from 3 Tac-I/Beta, which should have AMP activity $(\mathrm{P}<0.05)$. Reduction of the bacterial population was observed after 18 hours of bacterial growth in King B medium amendment with a solution of the filtered product 3 Tac-I/Beta.

Bacterial growth, expressed as optical density of cell culture, was reduced by around $12.1 \%$ when 3 Tac-I/Beta was used (ranked $=10.5-13.3 \%$ ), while the filtered solution of the concentrated formulation $4 \times 3$ Tac-I/Beta showed a reduction of around $34.8 \%$ after $18 \mathrm{~h}$ of co-culture, and $12.8 \%$ after $30 \mathrm{~h}$ of incubation. The concentrated filtered formulation's effect on bacterial growth was maintained between 18 and 26 hours, but this was lost after 30 hours. Commercial 3 Tac-I/Beta filtered solutions showed no differences when compared to the control after 26 hours. This situation showed that lytic enzymes present in 3 Tac-I/Beta have activity on the population of the bacteria but are unable to destroy all of them. Considering that he commercial formulation of 3Tac-I/ Beta contains the Trichoderma species, these myco antagonists could maintain a high amount of AMP production when the product is sprayed on plants. Filtered compounds of both products (3 Tac-I/ Beta and $4 \times 3$ Tac-I/Beta) used in the in vitro tests did not contain Trichoderma cells because we needed to avoid contamination when the absorbance readings were conducted. On the other hand, by filtering the compound we were not able to separate the concentration of hydroalcoholic compounds and micro traces of streptomycin present in the formulation of 3 Tac-I/Beta, which could explain the bactericidal activity observed in the Pss populations. However, higher inhibition on bacterial populations of P. syringae was observed when we used the product $4 \times 3$ Tac-I/Beta with four times the concentration of isoenzymes, suggesting that these AMPs isoenzymes play a role in dismissing bacterial cells.

3 Tac-I/Beta's AMPs activity was validated in the TEM study, which showed a marked damage on the membrane of P. syringaepv. syringae, which affected the bacillus shape of the bacterium by changing the continuity of the membrane compared to the control (Figure 1a \& 1b). Also, a close view of the bacterium cell wall and membrane allowed us to observe holes through which the cytoplasmic content of the cell was escaping (Figure 1c-1e). Moreover, the effect observed on the bacterial population was higher when the product was in contact with the bacteria during a period of 5 days. The AMPs of 3 Tac-I/Beta did not completely kill all of the bacteria, but its action could clearly reduce the growth of the bacterial population since several bacterial cells were affected, as shown in Figure 1f.

In vivo experiments showed that preventive spraying of 3 Tac-I/ Beta on cherry plants cv. Bing, which were wounded and inoculated with Pss 24 hours after spraying, evidenced differences in the length of the bacterial cankers compared to the untreated controls (Figure 2). Moreover, the biopesticide treatment was no different than the copper based treatments $(\mathrm{P}<0,10)$. The percentage of reduction compared to the control treatment was $29.5 \%$ when 3 Tac-I/Beta alone was used, while the use of 3 Tac-I/Beta with the biosurfactant did not significantly improve this product's results. Since reductions were only observed in the sprayings which were conducted in a preventive way, we may conclude that Trichoderma strains present in the formulation need time before they start producing more AMP compounds. Alcoholic compounds and streptomycin traces may also play a role in the initial activity of the product, but these compounds do not define the complete bactericidal and bacteriostatic activity of the product 3 Tac-I/ Beta. Moreover, empirical evidence showed that three spraying of 3 Tac-I/Beta in the season have a better control of bacterial stone canker in cherry sweet plants.

Copper oxide was able to reduce the disease in the inoculated site in a curative and preventive way compared to the control, which was not observed in treatments with copper hydroxide. On the other hand, 3 Tac-I/Beta showed no activity when it was sprayed curatively (Figure 2). 


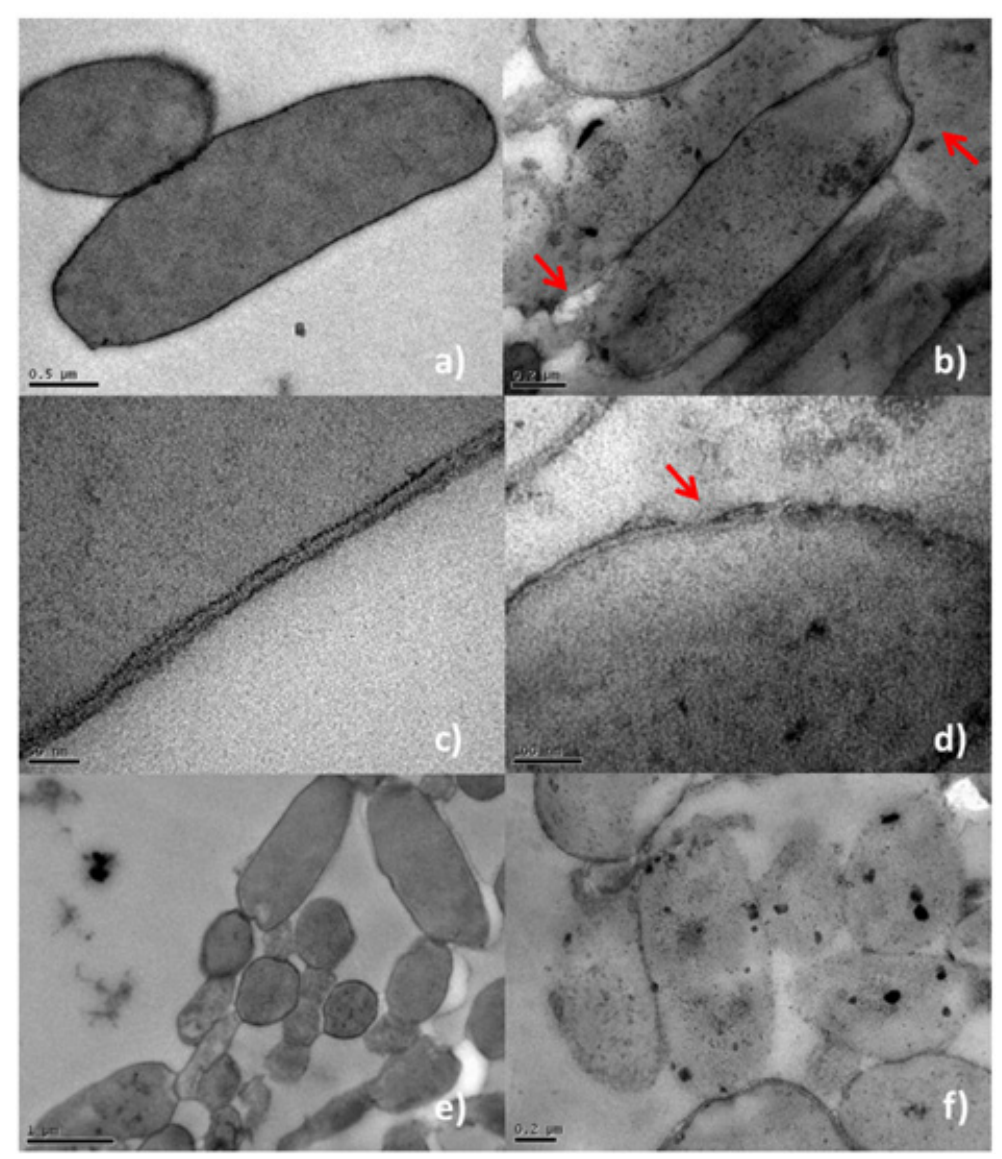

Figure 1: TEM pictures of Pseudomonas syringae pv. syringae strain PS3 cells treated with sterile distilled water (a, c, and d) and 3Tac - I / Beta (b, d, and f). A near view of the cell wall of the bacteria is observed, showing a healthy section of the control (c) and (d) a section with damage caused by the action of the product 3Tac-l/Beta. Red arrows indicate the emptying of the cytoplasmic contents of the cell and deformation in the cell wall shape. Black bars on each individual image are references to compare sizes of the objects.

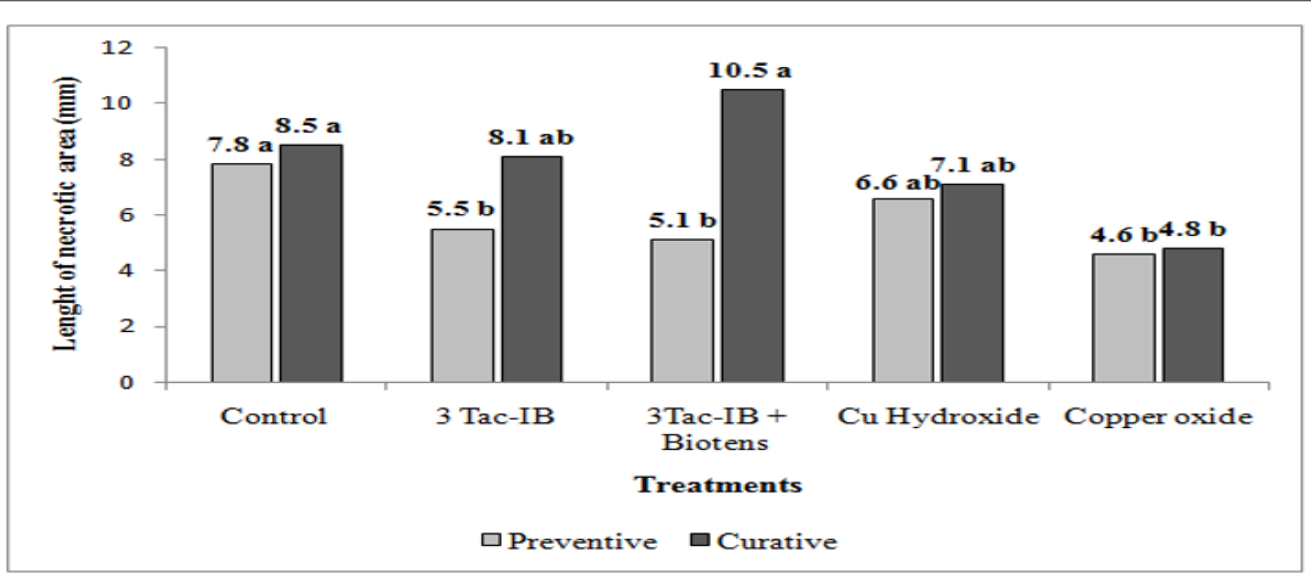

Figure 2: Average length of necrotized areas observed in cherry twig cultivars Bing, which were wounded and inoculated with Pseudomonas syringae pv. syringae, and treated once with different products in a preventive (before inoculation) and curative (after inoculation) way.

The suggested mode of action of 3 Tac-I/beta associated with the destruction of membrane integrity in bacteria should have four steps. In a first step, the polypeptides are inserted into the cellular membrane, so they can then interact among other polypeptides through hydrophobic sequences (second step) forming the membrane pore (third step). Additionally, there is an inhibition of the enzymes involved in cell wall formation, which has been described by Brogden [6]. Obviously, hydro alcoholic compounds and micro traces of streptomycin present in the product could play a role in reducing the product's effectiveness, especially considering that this antibiotic is a protein synthesis inhibitor, which binds to the small $16 \mathrm{~S}$ rRNA of the $30 \mathrm{~S}$ subunit of the bacterial ribosome, leading to cell death [7]. On the other hand, presence of Trichoderma species in the product 3 Tac-I/Beta could induce resistance in 
plants as has been described by Nawrocka and Malolepsza [8]; this variable should be assessed for this biopesticide in the future.

PSa is different than Pss because it did not produce the phytotoxin syringomicine, a lack of siderophore production, and exhibited a slow growth in King B media. However, bacterial membranes between Pss and PSa are probably very similar, thus 3 Tac-I/Beta could have similar effects on PSa compared to those observed on Pss. Studies on the efficacy of this biopesticide on PSa are currently being conducted.

\section{Conclusions}

a. The effect of 3 Tac-I/Beta on the bacterial growth of Pseudomonas syringae pv. syringae and the damage on cell wall membranes associated with antimicrobial peptides present in the compound was observed.

b. The AMP product 3Tac-I/Beta was able to reduce the necrotic area on Pseudomonas syringaepv. syringae inoculated branch tissue in sweet cherry plants.

\section{References}

1. Vanneste JL (2013) Recent progress on detecting, understanding and controlling Pseudomonas syringaepv. actinidiae: a short review. N Z Plant Protect 66: 170-177.
2. Vanneste JL, Kay C, Onorato R, Yu J, Cornish DA, et al. (2011) Recent advances in the characterization and control of Pseudomonas syringaepv. actinidiae, the causal agent of bacterial canker on kiwifruit. Acta Hort 913(59): 443-455.

3. Cameron A, Sarojini V(2014) Pseudomonas syringaepv. actinidiae: chemical control, resistance mechanisms and possible alternatives. Plant Pathol 63(1): 1-11.

4. Kennelly M, Cazorla FM, De Vicente A, Ramos C, Sundin GW (2007) Pseudomonas syringae disease of fruit trees: Progress toward understanding and control. Plant Dis 91(1): 4-17.

5. Eden PA, Schmidt TM, Blakemore RP, Pace NR (1991) Phylogenetic analysis of Aquaspirillum magnetotacticum with polymerase chain reaction-amplified 16S rRNA-specific DNA. Int J Syst Bacteriol 41(2): 324-325.

6. Brogden KA (2005) Antimicrobial peptides: pore formers or metabolic inhibitors in bacteria? Nat. Rev.Microbiol 3(3): 238-250.

7. Sharma D, Cukras AR, Rogers EJ, Southworth DR, Green R (2007) Mutational analysis of S12 protein and implications for the accuracy of decoding by the ribosome. J Mol Biol 374(4): 1065-1076.

8. Nawrocka J, Małolepsza U (2013) Diversity in plant systemic resistance induced by Trichoderma. Biol Control 67(2): 149-156. 